altogether; but with torrents transporting 5 per cent. and more of solid matter, and with the discharge of sewage; it is believed that the retarding power is quite appreciable. The whole question is no doubt a very complicated one; yet by a set of careful experiments, conducted with a view to discover this adhesive power of water, it appears highly probable that an important step would be gained, towards the solution of some other difficult but important problems.

The next point to consider is-How does water travel ? This also is a very abstruse question; but I believe that the true answer is given in the brief statement that water rolls rather than slides.

Were it not so, a ship with a foul bottom could not be so much retarded when passing through the water as experience shows she is. For example, supposing there are two ships in every respect the same, only that the first is covered with a coating of clean pitch a quarter of an inch thick all over her bottom to above her water line ; and that the second, in place of the pitch, has got all her bottom covered with marine animals and weeds, so that when this second ship is passing rapidly through the water, none of the sea-weeds or marine animals extend more than this $\frac{1}{4}$ inch beyond the ship's sides, which is the thickness of the coating of pitch on the first ship: in such a case the displacement and the lines are exactly the same, but it is hardly necessary to ask any sailor which of the two ships, with the same wind and sails, would pass most rapidly through the water, and, in the case of two steamers, the extra resistance caused by the foul bottom could be easily measured in extra horse power required to force the foul vessel through the water at a speed equal to the other.*

If the motion of the water was a sliding one only, the speed in both cases would be the same with the same power, for the resistance would be simply the separation of the two films of water, the one in contact with the ship's sides and the other with the surrounding sea; and these, in both cases, would be identical, the displacement being the same. If, however, as is believed, on a body passing through water, or water flowing down a channel, the particles of water are set in motion in a revolving direction, the convolutions increasing directly in proportion to the wetted surface, then by this hypothesis some assignable reason for this retarding of the foul-bottomed ship can be given.

If the particles slid over each other rather than rolled, they would, so to speak, pass each other in parallel straight lines; but any one in a gale of wind, going behind a high square block of building, would very soon discover that, in air, such is not the case : for if he went a few yards away in the direction the wind was blowing, he would soon discover that the building no longer afforded any protection from the blast, but that there was some certain point toleeward where the currents again converged, while beyond this the storm raged with the same violence as at any other point. (Every boatman knows what it is to get under the lee of a very high island; the sea may be smoother, but the sudden gusts of wind are often more dangerous than when exposed to the full force of the gale.) Immediately in rear of the wall itself he would find eddies of air whirling about in ali directions. Within the space

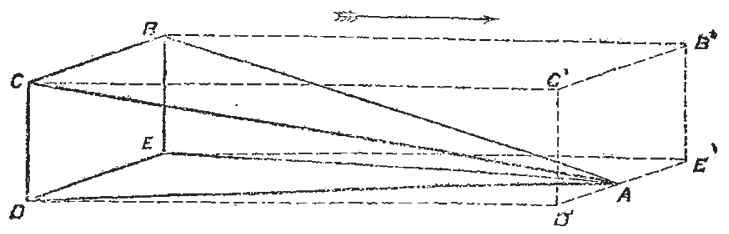

A B C D E there would be a partial protection from the storm, and instead of the wind being in the direction

* Possibly by the introduction of an elastic medium, such as air, between the ship's bottom and the water, the skin friction may be reduced, as it may, in a measure, reduce this rotatory action. shown by the arrow, there would be whirling eddies within this space, which could not exist were the air to pass off in straight lines as represented by the dotted lines $B B^{\prime}, C C^{\prime}, D D^{\prime}, E E^{\prime}$; neither could the several currents of air converge at the point $\mathrm{A}$, which it is well known is always the case.

In the same manner any obstruction placed in a stream of water, causes eddies in rear of it; that is to say, the water does not pass on in straight lines, but within this space it goes revolving about in all directions, the distance of A probably depending on the velocity : showing that there is neither a sliding motion nor a parallelism in the direction of the lines of current.*

\section{T. LOGIN}

\section{THE CLIMATE OF IRELAND}

$\mathrm{N}$ the science of nature there is no chapter more interesting than that which treats of Physical Geography, which, properly understood, means the account of physical phenomena as they are modified by geographical position and at the present moment the physical geography of Green Erin, or it speculiarities of soil and climate, presents a theme of no slight importance. It has been stated in the House of Commons as a proof of the retrograde condition of Ireland, that its production of cereals has of late years diminished, while its pasture lands have increased. To this it ought to have been answered that the decreased cultivation of cereals, and of wheat in particular, was a proof of improved knowledge. Years ago, at the meeting of the British Association in Cork, a communication was read, pointing out that agriculturists in general are governed wholly by example, their scanty science not allowing them to quit the beaten path. Hence Irish farmers, when they aim at improvement, endeavour to imitate the farming of Norfolk or the Lothians, and in so doing fail miserably, owing to the wide difference between the climates of the western isle and of the eastern side of Great Britain. It is commonly stated that Ireland has a very wet climate. It has undoubtedly a humid atmosphere, owing, perhaps, in some measure, to a great extent of undrained surface. But the total quantity of rain that falls in Ireland, little, if at all, exceeds the rainfall of England. In its distribution through the year, however, it differs much from the latter. The vicinity of the Atlantic gives Ireland in the highest degree an oceanic and, to some extent, an equatorial climate. Winter in the Green Isle is extremely mild. The southern and western coasts, though seldom free from wind and drizzling rain, never experience severe cold. Vegetation remains in mid-winter brilliantly green and undepressed. As spring advances, everything seems to flourish ; crops of all kinds promise abundance, and already, in May, harvest seems to be close at hand. But now the scene changes. There is little or no dry summer. When the sun is highest in the meridian, there is a constantly clouded sky and no sunshine. Rain begins to fall in June. The rainfall of July is the heaviest in the year. In August the rain begins to abate; but clear skies and bright sunshine cannot be reckoned on till September, when the shortened days and the sun's declination have much reduced the solar heat. The crops in the meantime, arrested in their progress, are not the better for two months' slumbering under the clouds They have summer rain in excess, and too little sunshine. From this it will be seen that the character of the Irish climate is, that under it everything grows well, but that the process of ripening is painfully slow and uncertain. Now, to cultivators of the cereals the success of this process is of the utmost importance. The corn harvest in Jreland falls late in the year, in September and October, when the days are short and nocturnal frosts not unfre-

* By an experimental study of this subject, it may be discovered how far these eddies cxtend with different velocities, which may throw light on 
quent. The plains of Southern Russia, or of the Red River in Canada, with a comparatively rigorous climate, far excel Ireland as wheat-producing countries, because their short summer is one of uninterrupted fierce sunshine; their vegetation suffers no check; the grain is ripened all at once, and the harvest gathered without delay or diffculty. The deficiency of ripening power in the Irish climate produces a secondary defect, which meets with less attention than it deserves. The grain which lingers on the stem two or three months before it hardens is sure to be unequally ripened; some of it is immature, while more is tending to decay. Consequently, it is bad seed, and the Irish farmer habitually sows perhaps six or eight times as much as $\mathrm{Mr}$. Mechi would deem requisite, Under these circumstances, it is evident that the Irish farmer ought to cultivate cereals no further than is requisite for the economy of his farm, and to look to other productions for his profit. Fortunately, there is a husbandry for the pursuit of which he enjoys peculiar advantages. In green crops no country can compete with Ireland, where, nevertheless, they are still little known or esteemed by the multitude. From this it may be inferred that sheep and cattle ought to be the chief objects of Irish husbandry. In truth, the Green Isle, under proper management, could easily supply England with beef, mutton, poultry, milk, and butter, and grow rich by giving abundance at a cheap rate to her neighbours. But then this could be effected only under a system of large farms. The grazier and cattle dealer, to make their business profitable, must do it on a large scale. Butter of the best quality cannot come from a small dairy. The improvement of Ireland, therefore, as dictated by climate and natural capability, can be effected only under a system of large farms. The popular wish, however, is for small holdings. It is thought that the country, when divided into potato gardens and all covered with cottages, will be a paradise. But this poor man's paradise, beginning with a few years of felicity, will assuredly lead to the pauperism of ages. The Legislature cannot countenance schemes opposed to the wholesome development of society, and which would make poverty an institution ; neither can it prevent their diffusion; but it may counteract them by spreading enlightenment and by presenting plain truths to the common sense of the community. This might be done by the publication of some statistics, showing the relative amount of cost and production of wheat and of green crops in England and Ireland, with some illustrations of the gain derivable from large farms and the use of machinery.

W. D. C

\section{THE STONE AGE IN EGYPT}

$A \mathrm{~T}$ a recent meeting of the French Academy, two A communications were read relatve to the discovery of relics presumably belonging to the Stone Age in Egypt. The one of these was merely a claim on the part of $M$. Arcelin to priority in the discovery of various localities abounding in such remains. The other, by Messrs. Hamy and Lenormant, while according priority in the discovery to $M$. Arcelin, gives a list of the various spots at present known in Egypt on which the manufacture of flint implements was carried on in early timesor where ateliers de fabrication have been discovered. For the benefit of our countrymen travelling in Egypt, we here reproduce the list, arranged in the order in which the places occur in travelling, southwards.

I. SAQQARAH, where have been found "scrapers" and other worked flints.

2. NEG-SALMANI, a small atelier in the desert, at some distance from the Libyan chain, and to the north of the ruins of Abydos. Flakes of whitish flint have been observed here.

3. HARABAT-EL-MADFOUNEH, another small atelier to the west of the great temple of Seti I., at the foot of the mountain. The worked flints, principally flakes, are of a fine texture, and pink in colour.
4. BAB-EL-MOLOUK, at the entry of the Valley of the Tombs. M. Arcelin here found fiakes, "scrapers," \&c.

5. GEBEL-QOURNAH. Here are traces of the manufacture on a large scale of worked flints of various types. Among these are said to be "lance-heads" of a curious character, like some of those from the Valley of the Somme, and the Cave of Le Moustier, arrowheads, knives with or without a shoulder, "scrapers," hammerstones, and nuclei, not unlike those of Pressigny. The flint is brown or blackish, and fine in texture.

6. DEIR-EL-BAHARI, and 7, DEIR-EL-MEDINEH, at the foot of the mountain of Thebes. Nuclei and flakes, like those of Gebel-Qournah, are found here occasionally, and it is suggested may have come from some unexplored locality on the summit.

8. EL-KAB, where, at the foot of the cliff, flakes, arrowheads, and other forms have been found.

Besides these localities, where worked flints occur on the surface of the soil, there is ABOU-MANGA, where the containing bed is not superficial, and some spots in the plain of Thebes, where MM. Hamy and Lenormant have found implements comparable in type with those of St. Acheul, and in connection with the old alluvia of the Nile, the relative date of which has, however, not been fixed.

It is stated that the instruments are not all of flint, but in some cases of porphyry, amphibolic rock, or other hard kinds of stone.

J. Evans

\section{THE PROTECTED CHANNEL RAILWAYS} III.

WE have already considered two modes of crossing the English Channel by a railway, viz. one above the water by a bridge, and another below the water by a tunnel through the chalk. The two shores might be also connected by a submerged roadway passing direct through the water. It might be constructed either on the bottom of the channel or at a certain distance below the level of the sea. Submerged roadways have been proposed, some of iron, others of concrete; of the forner of these we shall only consider such schemes as appear to have received sufficient attention from their originators.

These structures may be simply called tubes, because of their circular shape, which is, we all know, the most favourable form to resist pressure against collapse. The various propositions for the construction of iron tubes may be divided in two classes, viz. : Ist, schemes in which the parts of the proposed submerged tube are to be constructed on shore in certain lengths, afterwards to be united under water to form the permanent structure. and, Schemes in which the whole tube is to be at once built in deep water.

Among the designs which belong to the first class, the best and most elaborate is that of the late Mr. Chalmers. His design is well known from his publication on the Channel Railway, which we consider a meritorious and ingenious production. He proposes a line of tube between the South Foreland and Blanc-Nez on the French coast, with a gigantic tower-or ventilator, as he terms it-midway in the channel in thirty fathoms of water. Having made this tower, he proposes to construct wrought-iron tubes on shore, each about 400 feet long, closed at both ends by watertight bulkheads. These tubes are to be floated, one by one, to the tower, and to be there submerged, "being drawn down by means of endless chains passing round pulleys or drums attached to massive anchor boxes on the bottom of the Channel." The separate parts to be submerged at one operation are to have each a floating-power equal to about 100 tons. A short description is also given how the ends of the tube about to be submerged should be drawn and attached to that part already permanently secured to the tower and the bottom of the Channel. 